\title{
Effect of the chemistry and structure of the native oxide surface film on the corrosion properties of commercial AZ31 and AZ61 alloys.
}

Sebastián Feliu $(\mathrm{Jr})^{\mathrm{a}}$, C. Maffiotte ${ }^{\mathrm{b}}$, A. Samaniego ${ }^{\mathrm{a}}$, Juan Carlos Galván ${ }^{\mathrm{a}}$, Violeta Barranco ${ }^{\mathrm{a}, \mathrm{c}}$.

${ }^{a}$ Centro Nacional de Investigaciones Metalúrgicas CSIC, Avda. Gregorio del Amo 8, 28040 Madrid, Spain, (e-mail: sfeliu@cenim.csic.es), (e-mail: jcgalvan@cenim.csic.es)

${ }^{\mathrm{b}}$ CIEMAT. FNL (edificio 2), Avda. Complutense, 22, 28040 Madrid, Spain (email: cesar.maffiotte@ciemat.es)

'Instituto de Ciencias de Materiales de Madrid, ICMM, Consejo Superior de Investigaciones Científicas, CSIC, Sor Juana Inés de la Cruz, 3, Cantoblanco, 28049, Madrid, Spain

Corresponding author: Tel.:+34 91 5538900. Fax.: +34 91 5347425. Email address: sfeliu@cenim.csic.es

ABSTRACT: The purpose of this study has been to advance in knowledge of the chemical composition, structure and thickness of the thin native oxide film formed spontaneously in contact with the laboratory atmosphere on the surface of freshly polished commercial AZ31 and AZ61 alloys with a view to furthering the understanding of protection mechanisms. For comparative purposes, and to more fully describe the behaviour of the native oxide film, the external oxide films formed as a result of the manufacturing process (as-received condition) have been characterised. The technique applied in this research to study the thin oxide films (thickness of just a few nanometres) present on the surface of the alloys has basically been XPS (X-ray photoelectron spectroscopy) in combination with ion sputtering. Corrosion properties of the alloys were studied 
in $0.6 \mathrm{M} \mathrm{NaCl}$ by measuring charge transfer resistance values, which are deduced from EIS (electrochemical impedance spectroscopy) measurements after 1 hour of exposure. Alloy AZ61 generally showed better corrosion resistance than AZ31, and the freshly polished alloys showed better corrosion resistance than the alloys in as-received condition. This is attributed to a combination of (1) higher thickness of the native oxide film on the AZ61 alloy and (2) greater uniformity of the oxide film in the polished condition. The formation of an additional oxide layer composed by a mixture of spinel $\left(\mathrm{MgAl}_{2} \mathrm{O}_{4}\right)$ and $\mathrm{MgO}$ seems to diminish the protective properties of the passive layer on the surface of the alloys in as-received condition.

Keywords: Magnesium alloys, native oxide film; chemistry and structure; corrosion properties; XPS

\section{Introduction}

The chosen study materials are Mg-Al alloys, which have aroused great scientific and technological interest over the last two decades. From a practical point of view magnesium is the structural metal of lowest density, which makes it highly attractive for use in the automotive, aerospace, IT and electronics industries, as well as in the development of new biomaterials for orthopaedic and cardiovascular applications where weight plays a decisive role. However, as magnesium is one of the chemically most active metals, insufficient resistance to atmospheric and aqueous corrosion sometimes limits its applications. Thus it is desirable to have as complete as possible information on 
the factors that influence the corrosion of these materials. This work seeks to contribute to such information.

Many researchers have carried out studies to find relationships between the alloy microstructure (amount and distribution of $\beta$-phase precipitates) or the Al content in the bulk alloy and its corrosion resistance [1-12]. A much smaller number of researchers have studied the characteristics of the thin passivating layers on the surface of the metal, which are formed in contact with the atmosphere or in solutions of low aggressivity [13-26].

In immersion tests in saline solution, during the early stages of exposure (before the formation of visible black spots on the surface), the protective properties of the alloy seem to depend mainly on the chemistry and structure of thin native oxide films spontaneously formed in contact with the atmosphere. As Nordlien et al. [8,9] and Lunder et al [10] suggested, the original air-formed film is a highly stable form of oxide and preserves its properties when the specimen is exposed to the aqueous environment. Santamaria et al. [17] report that, in aqueous solution, a Mg hydroxide layer can grow while an ultra-thin $\mathrm{MgO}$ layer is maintained at the metal interface.

One of the main obstacles to obtaining information on the native oxide film is that of its small thickness (just a few nm), which is often too small to produce a sufficient signal for conventional materials characterisation techniques (SEM/EDX, XRD or TEM) [27]. In the present study highly promising results have been obtained with the surface analysis technique (XPS), which allows the analysed thickness to be reduced to only $3 \mathrm{~nm}$ and supplies information on the oxidation state of the detected element. Another drawback is that, as a result of 
the high affinity of magnesium to $\mathrm{O} 2, \mathrm{H} 2 \mathrm{O}, \mathrm{CO}$ and $\mathrm{CO} 2$, magnesium alloys react with the ambient atmosphere contaminating the surface. The outer layer of the native oxide film is spontaneously covered by a layer of hydroxyl and carbonate groups and destructive depth profile techniques such as ion sputtering have to be used. This technique may cause some artefacts as enrichment of elements in multi-component materials (preferential sputtering) [28], bond breaking and decomposition of oxides, phase formation, segregation, roughness formation [29]. Despite the possible bombardment-induced damage, in this study it will be shown that useful chemical and structural information has been obtained on the outer oxide films formed in the manufacturing process or on freshly polished surfaces and the innermost regions of the oxide film by depth profiling with XPS in combination with ion sputtering.

Oxide film formation and properties such as its protectiveness may be sensitive to the conditions under which it grows. Laboratory tests normally refer to the behaviour of surfaces that have been mechanically polished prior to testing, in order for metallographic observation and the removal of impurities and oxidation/corrosion product layers formed during the manufacturing process and subsequent storage of the alloy. However, it is of practical interest to obtain information on the chemical composition of the surface of the alloys in asreceived condition (untreated surface). In many applications magnesium alloys are used without further treatments [30], while on the other hand surface modification treatments such as conversion coating treatment are generally applied directly on the as-received surface, which may influence the formation and properties of these coatings [31]. From a scientific point of view, the literature contains controversial views relating to the effect of skin 
characteristics on the corrosion performance of magnesium alloys [32]. Song et al. [3] reported that the skin of die cast AZ91D showed better corrosion resistance than the interior. The opposite conclusion was obtained by $\mathrm{Yu}$ and Uan [33] and Zhang et al [30]. Recently, Song and Xu [34] have observed an improvement in the corrosion performance of AZ31B Mg alloy sheet by surface polishing. In general, these studies correlate corrosion properties with the microstructure of the skin layer and the impurity concentration.

The effect of aluminium as an alloying element on improving the corrosion resistance of magnesium has been studied by numerous researchers in a wide range of experimental conditions, such as exposure to dry oxygen [13, 35], to the ambient atmosphere $[14,15,36]$, to an atmosphere with a high degree of humidity [37-41], in immersion in distilled water [42], in saline solutions or atmospheres [1-5, 11, 12, 43-48], etc. In Mg-Al alloys, the greater affinity of aluminium for oxygen tends to produce surface films enriched in passivating aluminium oxide or mixtures of $\mathrm{Mg}$ and $\mathrm{Al}$ oxides, thus affording their outer surface special stability [2, 8, 9]. Nordlien et al. [2] and Anik et al. [49] observed that these changes are particularly significant when the aluminium content of the alloy is increased above $4 \%$, while further increases of aluminium above this threshold result in minor improvements. This threshold is characterised by a significant improvement in corrosion resistance. 


\section{Experimental}

2.1. Materials. The chemical compositions of the tested magnesium alloys, AZ31 and AZ61, are listed in Table 1. They were fabricated in wrought condition and supplied in plates of $3 \mathrm{~mm}$ thickness by Magnesium Elecktron Ltd.

Essential points of the metallurgical preparation of the sheet magnesium alloys, that may influence surface properties in the as-received condition, include heat treatment and hot rolling operations. Unfortunately, it has not been possible to obtain supplier's information on the various stages of manufacturing of the purchased AZ31 and AZ61 sheets used in the research. In the work we have tried to characterize the as-received conditions by analysis of XPS results, which are compared with those for the corresponding polished surfaces.

2.2. Surface conditions. The research compares the behaviour of specimens of the above alloys in the following surface conditions:

- Specimens in as-received condition, which means that the surface of the samples was untreated, only cleaned with distilled water and dried with hot air. As these were commercial specimens, we do not know the exact time of exposure to the atmosphere between manufacturing and characterisation.

- Freshly polished specimens. They were dry ground through successive grades of silicon carbide abrasive papers from P600 to P2000 followed by finishing with 3 and $1 \mu \mathrm{m}$ diamond paste, cleaned in water and dried with hot air. Due to the high affinity of magnesium to the ambient atmosphere, it was attempted to keep the exposure time to the 
atmosphere before characterisation of the specimens to a minimum, around 1 hour.

\subsection{Metallographic characterisation.}

Two etching reagents were used: (a) nital $2 \%, 2 \mathrm{ml} \mathrm{HNO} 3+98 \mathrm{ml} \mathrm{H} 2 \mathrm{O}$, to reveal the constituents and general microstructure of alloy AZ61, and (b) $4.6 \mathrm{~g}$ picric acid $+10 \mathrm{ml}$ acetic acid $+70 \mathrm{ml}$ ethanol $+10 \mathrm{ml} \mathrm{H} 2 \mathrm{O}$ to reveal the grain boundaries of alloy AZ31.

The tested specimens were examined by scanning electron microscopy (SEM) using a JEOL JXA 840A unit operating with Rontec EDR288 software for EDX spectra acquisition and image digitalisation.

\subsection{XPS analysis.}

XPS analysis was performed with a Perkin-Elmer PHI 5400 spectrometer equipped with a Mg Ka excitation source $(\mathrm{hv}=1253.6 \mathrm{eV})$ and a beam size of 1 $\mathrm{mm}$ diameter. The spectrometer was calibrated using copper, gold and silver standards. Typical operation conditions were: X-ray gun, 15 kV, $20 \mathrm{~mA}$; pressure in the sample chamber $\sim 10^{-9}$ Torr; pass energy, $89.50 \mathrm{eV}$ for general spectra $(0-1100 \mathrm{eV})$ and $35.75 \mathrm{eV}$ for high resolution spectra. In order to take into account the charging effects on the measured binding energies, these energies have been determined by referencing to the adventitious $C$ 1s peak at $284.8 \mathrm{eV}$. The intensities were estimated by calculating the area under each peak after smoothing and removing the background using the modified method of Shirley and adjusting the experimental curve to a Gaussian-Lorentzian ratio 
variable curve using an iterative algorithm. The measurements were performed at take-off angles of $45^{\circ}$ with respect to the sample surface. The analysis area was $1 \mathrm{~mm} \times 1 \mathrm{~mm}$, therefore, Gray Munro et al. [21] indicate that with this analysis area XPS results give an average surface chemistry over all phases of the material.

Composition-depth profiling was performed by sequential XPS surface analysis and ion sputter etching using a $4.0 \mathrm{keV}$ argon ion flux. Calibration of the ion sputter etching rate $\left(5 \mathrm{~nm} \cdot \mathrm{min}^{-1}\right)$ was achieved by depth profiling a SiO2 thin film of known thickness. The actual sputtering rate was determined from the change in oxide film thickness. Pressure in the sample chamber during this process was $\sim 10^{-7}$ Torr. (bombardment). C1s, O1s, Mg2p, Al2s and Ca2p high resolution XPS spectra were obtained on the surface of the samples in asreceived condition after $0.5,1.25,2,3,4.25,5,6.5,10,15,17,20,25,30$ and 40 minutes of ion sputtering.

2.5. EIS measurements. Electrochemical impedance measurements were conducted in $0.6 \mathrm{M} \mathrm{NaCl}$ after 1 hour of exposure at room temperature $\left(25^{\circ} \mathrm{C}\right)$. An AUTOLAB potentiostat, model PGSTAT30, with frequency response analyser (FRA) software was used. The frequency ranged from $100 \mathrm{kHz}$ to 1 $\mathrm{mHz}$ with 5 points/decade, whereas the amplitude of the sinusoidal potential signal was $10 \mathrm{mV}$ with respect to the open circuit potential. A typical threeelectrode set-up was employed: $\mathrm{Ag} / \mathrm{AgCl}$ and graphite were used as reference and counter electrodes, respectively, and the material under study was the working electrode.

\subsection{Low Angle X-Ray diffraction measurements}


X-ray diffraction (XRD) measurements were carried out with a Bruker AXS D8 diffractometer in grazing incidence condition. In the setup used, a X-ray Co tube is equipped with a Goebel mirror optics to obtain a parallel and monochromatic X-ray beam. A current of $30 \mathrm{~mA}$ and a voltage of $40 \mathrm{KV}$ were employed as tube setting. XRD data were collected with a beam incidence angle of $1^{\circ}$ and $2 \theta$ scan between 20 and $110^{\circ}$ with a step size of $0.03^{\circ}$ and a counting time of $4 \mathrm{~s} / \mathrm{step}$

\section{Results and discussion}

\subsection{Microstructure of the tested materials}

As can be seen in Figure 1, the microstructure of alloy AZ31 is formed almost entirely of the a-matrix (Fig. 1b), whereas in the microstructure of alloy AZ61 a considerable part of the aluminium has precipitated in the form of $\beta$-phase at the grain boundaries (Fig. 1a).

\section{2. $M g 2 p$ XPS spectra}

The evolution with sputtering time of the Mg2p high resolution XPS spectrum obtained on the native oxide film formed spontaneously on the surface of alloys AZ31 and AZ61 in polished condition is shown in Figures 2a-2h. The spectra obtained for other sputtering times are fairly similar and are not shown. Throughout the work, in order to avoid repeating similar spectra, only those necessary to support the corresponding facts are displayed. The spectra obtained on the non-sputtered surface (Figs 2a-2b) are fairly similar, containing one single component at a binding energy of $50.8 \mathrm{eV}$ associated with the 
presence of magnesium in the form of magnesium hydroxide/carbonate [22]. Figures $2 c-2 d$ show the spectra obtained after 3 minutes of sputtering. This was the shortest sputtering time necessary for the appearance of a small shoulder, at a binding energy of $49.7 \mathrm{eV}$, associated with the presence of magnesium in metallic state in alloy AZ31 (Fig 2c). In contrast, no such shoulder is seen on alloy AZ61 (Fig. 2d). After 5 minutes of sputtering, the intensity of the metallic magnesium component is similar to that of Mg2+ in the case of alloy AZ31 (Fig. 2e) or lower in the case of alloy AZ61 (Fig. 2f). During these first 5 minutes of sputtering, the absence of significant changes in the binding energy of the Mg2+ signal tends to support the claim that sputtering does not alter the oxidation states of surface species. After ten minutes of sputtering (Figs. $2 \mathrm{~g}-2 \mathrm{~h}$ ) a shift of approximately $0.6 \mathrm{eV}$ towards lower binding energies of the second component which may be associated with an artefact of sputtering due to bond breaking and decomposition of magnesium oxides.

The metallic $\mathrm{Mg}$ at $49.7 \mathrm{eV}$ could originate from either bulk metallic magnesium or islands of metallic magnesium beneath the oxide films, depending on the uniformity of this outer film [22]. XPS in combination with ion sputtering data may resolve this ambiguity. If the Mg2p emission at $49.7 \mathrm{eV}$ was from metallic islands within the oxide film, the ratio of its intensity to that of the oxide peak would not vary significantly with ion sputtering, otherwise the intensity should increase as the sputtering time increases. The Mg2p spectra in Fig. 2 demonstrates that the ratio of the area of metallic Mg2p at $49.7 \mathrm{eV}$ to that of the oxide Mg2p peak at $50.8 \mathrm{eV}$ increases with sputtering time. This suggests that the emission at $49.7 \mathrm{eV}$ is mainly from metallic magnesium beneath the magnesium oxide thin film, rather than from the surface islands of metallic 
magnesium, which is consistent with the layer by layer film growth mechanism discussed by Yao et al. [22]. Also, the rapid and continuous increase in the magnesium content and the reduction in the oxygen content after sputtering (Figs. $3 \mathrm{a}$ and $3 \mathrm{~b}$ ) tend to suggest that the $\mathrm{MgO}$ layer formed spontaneously in contact with the laboratory atmosphere on the surface of the AZ31 and AZ61 alloys as a result of the polishing process is a fairly homogeneous film [19].

\subsection{Al2s XPS spectra}

Due to strong overlap between the second bulk plasmon of the metallic Mg2p peak and the Al2p peak observed in our measurements, we have measured the Al2s peak instead of the Al2p peak [50]. The evolution with sputtering time of the Al2s high resolution XPS spectrum obtained on the oxide film formed spontaneously on the surface of alloys AZ31 and AZ61 in freshly polished condition is compared in Figures $4 \mathrm{a}-4 \mathrm{~h}$. The spectra obtained on the nonsputtered surface (Figs. 4a-4b) contain one single component at a binding energy between 119.3-119.7 eV associated with the presence of aluminium in the form of Al3+. In contrast to alloy AZ31 (Fig. 4c), attention is drawn to the presence of a significant metallic Al signal, which appears at approximately $117.3 \mathrm{eV}$, in the spectrum obtained on alloy AZ61 after 3 minutes of sputtering (Fig. 4d), whose intensity tends to rise with sputtering time (Figs. $4 \mathrm{f}$ and $4 \mathrm{~h}$ ). On alloy AZ31, no appreciable changes have been observed in the shape or position of the spectra after longer sputtering times (Figs. $4 \mathrm{e}$ and $4 \mathrm{~g}$ ). The evolution of the oxidation state of aluminium, observed by XPS, in the Mg-AI alloys with depth profiling has been assessed in very few studies. We have not 
found data about alloy AZ61, only metallic Al peaks have been detected on AZ91 alloys by Liu et al. [51] and Wang et al. [52], and significant quantities of Al2O3 have been detected on AZ31 alloys after prolonged sputtering by Wang et al [53-56] and, Wang [57].

Of relevance to understanding the corrosion behaviour of aluminium alloying elements is their chemical state, and particularly whether they are in a metallic state in solid solution or forming aluminium oxide particles in the outer region of the material. Alloy AZ61, which contains 6\%Al (Table 1), could have accessed this aluminium in metallic or free form (Fig. 4h) for surface enrichment during the subsequent corrosion process. In alloy AZ31, which contains 3\%AI (Table 1), the absence of a significant metallic aluminium signal (Fig. $4 \mathrm{~g}$ ) suggests the absence of a significant amount of this element within the detection limits of the XPS spectrometer, perhaps because a large part of the Al is not in solid solution but present as aluminium oxide particulates. This difference seems to correspond with the significant increase in the Al content detected on the surface layers formed during the corrosion process when the alloy's aluminium content is increased above 4\% [8] and Anik et al. [49].

\subsection{C1s XPS spectra}

Figure 5 shows a comparison of the high-resolution C1s XPS spectra for alloys AZ31 and AZ61. The spectra can be fitted using two components at different binding energies: at $285.0 \mathrm{eV}$, which may be associated with the presence of $\mathrm{C}$ _ $\mathrm{C} / \mathrm{C} \_\mathrm{H}$ groups; and a less intense component about 4.5-5.0 eV higher which is associated with the presence of magnesium carbonate [22]. The first component, $C_{-} \mathrm{C} / \mathrm{C}_{-} \mathrm{H}_{\mathrm{H}}$ groups, appears on the outer surface $(<3 \mathrm{~nm}$ in 
thickness) of almost any metal in contact with the atmosphere at room temperature, irrespective of its composition. Magnesium carbonate formation can be explained by the diffusion of $\mathrm{CO} 2$ from the environment and its reaction with the oxide film on the freshly polished surface [41]. Table 2 shows the area of the magnesium carbonate component calculated from the fitting of $\mathrm{C} 1 \mathrm{~s}$ spectra (Fig._5). Due to the small differences in the atomic percentage of carbonate obtained from the C1s spectra on the surface of the AZ31 and AZ61 alloys, we have chosen to compare the area of this component. It is important to note that the amount of magnesium carbonate was higher on the sputtered AZ61 alloy than on the AZ31 alloy. In a previous study [26] some correspondence was observed between the presence of $\beta$-phase (Mg17Al12) and the amount of magnesium carbonate formed on the surface after atmospheric exposure. The results of this work tend to support this behaviour. From the point of view of magnesium alloy protection mechanisms, the formation of a carbonate product layer, thicker than that observed in this work, provides better passivation of the surfaces and retards chloride-induced corrosion in the passivation zone [20].

\subsection{Chemistry and structure of outer oxide surface layer formed on AZ31 and}

\section{AZ61 alloys in as-received condition}

From the point of view of the chemical composition of the oxide layer, attention is drawn to the presence of significant amounts of $\mathrm{Ca}$ on the non-sputtered surface of alloys AZ31 and AZ61 in as-received condition and their absence in polished condition (Table 3). It is also important to note the absence of 
significant amounts, within the detection limits of our XPS spectrometer, of other alloying elements such as $\mathrm{Zn}, \mathrm{Mn}, \mathrm{Si}$ and $\mathrm{Fe}$ on the surface of the studied alloys.

It is interesting to note that the Ca content observed in the XPS analysis of the outer surface of the as-received alloys tends to decline quickly with sputtering time (Table 3), probably because the presence of a significant calcium content in oxide form is limited to the outermost surface of the magnesium specimens $[24,25]$. This result is similar to that obtained by $R$. Souda et al. [58] who, working with $\mathrm{MgO}$ crystals including $210 \mathrm{ppm}$ bulk $\mathrm{Ca}$ impurities, found that $\mathrm{Ca}$ ions were detected only in the outermost layer and that $\mathrm{Ca}$ enrichment did not take place in the deepest layers.

The $\mathrm{Al} /(\mathrm{Mg}+\mathrm{Al})$ ratio determined by XPS after 10 minutes of sputtering is about 4 and 9 at\% for the polished surfaces of alloys AZ31 and AZ61, respectively (Table 3). It should be noted that in as-received condition, and for the same sputtering time, this ratio is 29 at\% for alloy AZ61, notably higher than in the polished condition.

The $\mathrm{O} /(\mathrm{Mg}+\mathrm{Al})$ atomic ratios obtained by XPS on the surface of alloys AZ31 and AZ61 for increasing sputtering times (Table 3) provide an approximation to the Mg-Al-O stoichometry of the surface oxide [59]. O/(Al+Mg) ratios of 1.2-1.5 are observed on the AZ61 and AZ31 alloys in as-received condition during the first 15 minutes of sputtering. These values are close to the theoretic value of 1.33 for spinel (MgAl2O4), although if this compound were to form its proportion in the oxide film would be relatively small considering the $\mathrm{Al} /(\mathrm{Mg}+\mathrm{Al})^{*} 100$ ratios in Table 3, far from the theoretic value of 66 for spinel. Czerwinski [27] 
commented that during gradual oxidation of an AZ91 alloy, Al reacts to form MgAl2O4 spinel. By using XPS analyses in combination with ion sputtering, Shih et al. [60] have observed the presence of an admixture of $\mathrm{Mg}$-Al oxides or spinel (MgAl2O4) in $\mathrm{MgO}$ when characterising the surface of the solutiontreated AZ80 magnesium alloy.

Figures $3 \mathrm{c}$ and $3 \mathrm{~d}$ show how the oxygen and magnesium contents observed on the alloys in as-received condition remain approximately stable during the first 15 minutes of sputtering before subsequently decreasing and increasing, respectively, after longer times. According to Nakano et al. [61], in films with a thin homogeneous layer the intensity of chemical compounds present in the outer layer should decrease linearly with sputtering time. However, the decay for the 3-D islands structure shows a progressively steeper slope with time. In contrast to the presence of a fairly homogenous $\mathrm{MgO}$ layer noted above for the alloys in polished condition, this data tends to suggest that the outer layer that grows on the alloys in as-received condition has a heterogeneous islands structure. In the hypothesis that all the Al included in the data in Table 3 were to be dedicated to the formation of spinel islands thick enough to avoid the magnesium signal coming through, around $25-30 \%$ of the alloy AZ61 surface would be covered by spinel, a percentage that would be approximately halved in the case of alloy AZ31.

SEM examinations of the AZ61 alloy in as-received condition (Fig. 6b) revealed a rough surface covered with non-uniform features, very different to that of the polished surface (Fig. 6a). In EDX analyses obtained on the surface of the alloys in as-received condition, attention is drawn to the increase in the Al 
content and the decrease in the $\mathrm{Mg}$ content in spectra 1 and 4, compared to spectra 2 and 3 (Table 4, Fig. 6b). Furthermore, the Al percentage detected in spectra 1 and 4 is higher than its bulk content (6\%). These figures tend to confirm, on the one hand, a non-uniform distribution of aluminium and magnesium, and on the other hand a surface enrichment of Al on the AZ61 alloy in as-received condition, as previously observed by XPS.

\subsection{Oxide film thickness}

The thickness of the native oxide film on the surface of the magnesium specimens was calculated using the expression given by Strohmeier [62]:

$\left.\mathrm{d}_{\mathrm{o}}(\mathrm{nm})=\lambda_{\text {oxide }} \sin \theta \ln \left[\mathrm{I}_{\text {oxide }} \times \lambda_{\text {metal }} \times \mathrm{N}_{\mathrm{m}}\right) /\left(\mathrm{I}_{\text {metal }} \times \lambda_{\text {oxide }} \times \mathrm{N}_{\mathrm{o}}\right)+1\right](1)$

where $d_{0}$ is the thickness of the magnesium oxide layer (in $n m$ ); $\theta$ is the photoelectron output angle; $I_{\text {metal }}$ and $I_{\text {oxide }}$ are the intensities of the magnesium components in the metallic state and as oxide from the Mg2p peak; $\lambda_{\text {metal }}$ and $\lambda_{\text {oxide }}$ are the mean free paths of photoelectrons in the substrate and the oxide layer; and $\mathrm{N}_{\mathrm{m}}$ and $\mathrm{N}_{\circ}$ are the volume densities of magnesium atoms in metal and oxide. The values of $\lambda_{\text {metal }}$ and $\lambda_{\text {oxide }}$ are 3.0 [63] and $2.6 \mathrm{~nm}$ [64], respectively, [65], and an $\mathrm{N}_{\mathrm{m}} / \mathrm{N}_{\circ}$ ratio of 1.24 was used [18]. Figure 7 shows the oxide film thickness as calculated from Eq. 1 for the Mg2p peak after 3 min (Figs. 2c and 2d), 4.25 min (not shown), 5 min (Figs. 2e and 2f) and 6 min of sputtering (not shown) in the polished condition; and after 17 min (not shown), 20 min (Figs. 2s and 2t), 25 min (not shown), and 30 min of sputtering (Figs. $2 n$ and $2 \mathrm{v}$ ) in as-received condition. Following the approach proposed by McCafferty et al. [66], the oxide film thickness before sputtering was determined 
by extrapolation of the linear portion of Figure 7 (thicknesses after ion sputtering) back to zero sputter time.

It is interesting to note that the thickness of the oxide film on the AZ61 alloy is higher than that observed on the AZ31 specimens (Figure 7). Thickness differences (of $\mathrm{nm}$ order) in the native oxide layer formed spontaneously on metallic materials have been related with the presence of imperfections or heterogeneities where the film is more pervious to the movement of the reaction products $[15,27,67]$. In the commercial magnesium alloys tested in this work there also seems to be a direct relationship between the native oxide film thickness and the degree of microstructural complexity of the surface upon which it forms. Figure 1 shows a very significant presence of $\beta$ intermetallic phase on the boundary of AZ61 (Fig. 1a) compared to its absence on AZ31 (Fig. 1b).

Figures $7 c-7 d$ show the oxide film thickness as calculated from Eq. 1 for the Mg2p peak after $17 \mathrm{~min}$ (not shown), 20 min (Figs. 2s and 2t), 25 min (not shown) and 30 min of sputtering (Figs. 2u and 2v), for alloys AZ31 and AZ61 in as-received condition. With an oxide with non-uniform growth (island model), the oxide thickness and sputtering rate obtained can be used only as an estimate [62]. It is interesting to note the reduction in the sputtering rate of the alloys in as-received condition ( $1 \AA / \mathrm{min}$ ) compared to the alloys in polished condition (3-5 $\AA / \mathrm{min})$. It is important to remember that the sputtering rate is different for different materials [19]. Nenadovic et al. [68] observed that the sputtering yield of $\mathrm{Al} 2 \mathrm{O} 3$ is close to four times lower than the sputtering yield of $\mathrm{MgO}$ at $4 \mathrm{KeV}$ (sputtering energy used in our work). From the results of the present work it would be possible to speculate that the important segregation of 
Al to the surface to precipitate in the form of MgAl2O4 spinel-type oxide must have led to the reduction in sputtering rate values of the alloys in as-received condition.

Figure 8 presents the low angle X-ray diffraction pattern for the AZ31 (a) and AZ61 alloys (b) in "as-received condition". The diffractogram for the AZ31 and AZ61 alloys in polished condition were fairly similar to that acquired on the AZ31 alloys in "as-received condition" and are not shown. In contrast with the other samples (Fig. 8a), the diffractrogram of the AZ61 alloy in as "received condition" seems to show a small intensity peak of periclasa (MgO) (Fig. 8b) due to the formation of a thicker oxide layer during the manufacturing process.

\subsection{Relations between the chemistry and structure of thin outer oxide films and} the corrosion properties of commercial AZ31 and AZ61 alloys

It seems likely that some differences revealed in the composition and characteristics of oxide films formed on alloys AZ31 and AZ61 may have an impact on the corrosion behaviour of the specimens. In this respect, attention is drawn to: (a) the uniformity of the oxide film; (b) its degree of heterogeneity; (c) its greater thickness; and (d) a higher percentage of surface covered by spinel. Table 5 (column 3) shows the occurrence of these features as a function of surface conditions and alloy type (column 1).

Numerous studies in the literature support the use of impedance spectra to obtain information on the corrosion process. In the case of magnesium alloys, the diameter of the capacitive loop $\left(R_{H F}\right)$ in the high frequency region of the diagram (Fig. 9) is normally associated with the charge transfer resistance of 
the corrosion process, for which reason it is inversely related with the corrosion rate.

The lowest $R_{H F}$ value corresponds to the as-received surface of alloy AZ31, which, as a special feature, shows the presence of spinel islands in the outermost surface of the oxide film, the small fraction of spinel does not seem to exert any special effect for corrosion protection. In the same alloy, but for the freshly polished condition, the $R_{H F}$ value increases significantly (by a factor of 3.3), the absence of spinel and the uniformity of the oxide film is now the special features to notice. These data tend to suggest that the growth of an additional layer of spinel islands on the surface of the as-received alloy, which modify the structure of the native oxide film, making it more defective, may decrease its protective properties. Comparison between $R_{H F}$ values for alloys for alloys AZ31 and AZ61 both now in freshly polished condition shows a notably higher value for alloy AZ61 which presents a greater oxide film thickness. Finally, with the alloys in the as-received condition, the $\mathrm{R}_{\mathrm{HF}}$ value for AZ61 alloy is higher than that corresponding to AZ31. XPS analysis has revealed as a special feature a larger fraction of AZ61 alloy surface covered by islands of spinel. One may speculate, that the outer surface of the AZ61 alloy in "as-received condition" may be more restrictive for the diffusion of magnesium atoms from the alloy substrate during the posterior corrosion process.

\section{Conclusions}

Using XPS analysis, notable differences have been shown in the oxide films formed on the surface of AZ31 and AZ61 alloys in as-received and freshly polished conditions. Points to be noted are the degree of heterogeneity of the 
films coating as-received surfaces compared to the uniformity of the films formed on freshly polished surfaces; the greater thickness of the oxide film on the polished AZ61 alloy surface; and, in the case of alloy AZ61, the presence of a higher proportion of spinel with the magnesium oxide that mainly forms the oxide film.

The charge transfer values, $\mathrm{R}_{\mathrm{HF}}$, obtained from EIS measurements on the specimens after 1 hour of immersion in $0.6 \mathrm{NaCl}$ solution have allowed possible relationships between surface characteristics and corrosion resistance to be explored. In the joint analysis of XPS and EIS data, attention is drawn to the increase in the $R_{H F}$ value on freshly polished specimens compared to the asreceived surfaces. This effect is especially seen on the AZ61 alloy.

\section{Acknowledgment}

We wish to express our gratitude to Prof. S. Feliu for several clarifying and stimulating discussions during the course of this work. Also, the authors gratefully acknowledge the financial support for this work from the Ministry of Science and Innovation of Spain ( MAT 2009-13530) 
Referencias

[1] G. Ballerini, U. Bardi, R. Bignucolo, G. Ceraolo, About some corrosion mechanisms of AZ91D magnesium alloy, Corros. Sci., 47 (2005) 21732184.

[2] G. L. Song, A. Atrens, X.L. Wu, B. Zhang, Corrosion behaviour of AZ21, AZ501 and AZ91 in sodium chloride, Corros. Sci. 40 (1998) 1769-1791.

[3] G. L. Song, A. Atrens, M. Dargusch, Influence of microstructure on the corrosion of diecast AZ91D, Corros. Sci. 41 (1999) 249-273.

[4] R. Ambat, N.N. Aung, W. Zhou, Evaluation of microstructural effects on corrosion behaviour of AZ91D magnesium alloy, Corros. Sci. 42 (2000) 1433-1455.

[5] G.L. Song, A. Atrens, Corrosion mechanisms of magnesium alloys, Adv. Eng. Mat. 1 (1999) 11-33.

[6] S. Mathieu, C. Rapin, J. Hazan, P. Steinmetz, Corrosion behaviour of high pressure die-cast and semi-solid cast AZ91D alloys, Corros. Sci. 44 (2002) 2737-2756.

[7] G. Galicia, N. Pebere, B. Tribollet, V. Vivier, Local and global electrochemical impedances applied to the corrosion behaviour of an AZ91 magnesium alloy, Corros. Sci., 51 (2009) 1789-1794.

[8] J.H. Nordlien, K. Nisancioglu, S. Ono, N. Masuko, Morphology and structure of oxide films formed on MgAl alloys by exposure to air and water, J. Electrochem. Soc. 143 (1996) 2564-2572.

[9] J.H. Nordlien, K. Nisancioglu, S. Ono, N. Masuko, Morphology and structure of water-formed oxides on ternary MgAl alloys, J. Electrochem. Soc. 144 (1997) 461-466. 
O. Lunder, J.E. Lein, T. K. Aune, K. Nisancioglu, The role of

$\mathrm{Mg}_{17} \mathrm{Al}_{12}$ phase in the corrosion of Mg alloy AZ91, Corrosion 45 (1989) 741-748.

A. Pardo, M.C. Merino, A.E. Coy, R. Arrabal, F. Viejo, E. Matykina, Corrosion behaviour of magnesium/aluminium alloys in 3.5 wt.\% NaCl, Corros. Sci. 50 (2008) 823-834.

A. Pardo, M.C. Merino, A.E. Coy, F. Viejo, R. Arrabal, S. Feliu Jr., Influence of microstructure and composition on the corrosion behaviour of Mg/Al alloys in chloride media, Electrochim. Acta, 53 (2008) 78907902.

[13] V. Fournier, P. Marcus, I. Olefjord, Oxidation of magnesium ,Sur. Interface Anal. 34 (2002) 494-497.

[14] C. Fotea, J. Callaway, M.R. Alexander, Characterisation of the surface chemistry of magnesium exposed to the ambient atmosphere, Surf. Interface Anal. 38 (2006) 1363-1371.

N.S. McIntyre, C. Chen, Role of impurities on Mg surfaces under ambient exposure conditions, Corros. Sci. 40 (1998) 1697-1709. oxide film growth on $\mathrm{Mg}$ and $\mathrm{Al}$ surfaces over extended periods using XPS , Surf. Sci. 382 (1997) L.652-L657.

[17] M. Santamaría, F.Di Quarto, S. Zanna, P. Marcus, Initial surface film on magnesium metal: A characterization by X-ray photoelectron spectroscopy (XPS) and photocurrent spectroscopy (PCS), Electrochim. Acta 53 (2007) 1314-1324. 
[18] M. Liu, S. Zanna, H. Ardelean, I. Frateur, P. Schmutz, G.L. Song, A. Atrens, P. Marcus, A first quantitative XPS study of the surface films formed, by exposure to water, on $\mathrm{Mg}$ and on the $\mathrm{Mg}-\mathrm{Al}$ intermetallics: $\mathrm{Al}_{3} \mathrm{Mg}_{2}$ and $\mathrm{Mg}_{17} \mathrm{Al}_{12}$, Corros. Sci. 51 (2009) 1115-1127.

Song, A. Atrens, P. Marcus, Electrochemical reactivity, surface composition and corrosion mechanisms of the complex metallic alloy $\mathrm{Al}_{3} \mathrm{Mg}_{2}$, Corros. Sci. 52 (2010) 562-578.

[20] L. Wang, T. Shinohara, B.P. Zhang, XPS study of the surface chemistry on AZ31 and AZ91 magnesium alloys in dilute $\mathrm{NaCl}$ solution, Appl. Surf. Sci. 256 (2010) 5807-5812.

[21] J.E. Gray-Munro, B. Luan, L. Huntington, The influence of surface microchemistry in protective film formation on multi-phase magnesium alloys, ,Appl. Surf. Sci. 254 (2008) 2871-2877.

[22] H.B. Yao, Y. Li, A.T.S. Wee, An XPS investigation of the oxidation/corrosion of melt-spun Mg, ,Appl. Surf. Sci. 158 (2000) 112119. study of the effect of aluminium on the atmospheric corrosion of the AZ31 magnesium alloy, Sur. Interface Anal., 41 (2009) 143- 150. Arrabal, The Application of X-Ray Photoelectron Spectroscopy in Understanding Corrosion Mechanisms of Magnesium and Mg-Al Alloys, The Open Surface Science Journal, 3 (2011), 1-14. 
S. Feliu Jr., J.C. Galván, A. Pardo, M.C. Merino, R. Arrabal, Native Air-Formed Oxide Film and its Effect on Magnesium Alloys Corrosion, The Open Corrosion Journal, 3 (2010) 80-91. Correlation between the surface chemistry and the atmospheric corrosion of AZ31, AZ80 and AZ91D magnesium alloys, Appl. Surf. Sci. 255 (2009) 4102-4108. alloy at high temperatures, Acta Mater. 50 (2002) 2639-2654.

[28] F. Reichel, L.P.H. Jeurgens, E.J. Mittemeijer, Modeling compositional changes in binary solid solutions under ion bombardment: Application to the Ar+ bombardment of MgAl alloys, Phys. Rev B. 73 (2006) ARTN 024103.

[29] S. Oswald, R. Reiche, Binding state information from XPS depth profiling: capabilities and limits. Appl. Surf. Sci. 179 (2001) 307-315

[30] W. Zhang, S. Jin, E. Ghali, R. Tremblay, Skin and bulk corrosion properties of die cast and thixocast AZ91D magnesium alloy in $0.05 \mathrm{M}$ $\mathrm{NaCl}$ solution, Can. Metall. Q. 45 (2006) 181-188.

[31] Y.L. Lee, C.S. Lin, Influence of Die-Chill Skin on the Formation of Stannate Conversion Coating on AZ91D Magnesium Alloy, J. Electrochemical Soc. 157 (2010) C187-C193.

[32] E. Aghion, N. Lulu, The effect of skin characteristics on the environmental behavior of die cast AZ91 magnesium alloy, J. Mater. Sci. 44 (2009) 4279-4285. 
B.L. Yu, J.Y. Uan, Correlating the microstructure of the die-chill skin and the corrosion properties for a hot-chamber die-cast AZ91D magnesium alloy, Metall. Mater. Trans. A. 36A (2005) 2245-2252.

$$
\text { G.L. Song, Z. Xu, Improving corrosion performance of AZ31B Mg }
$$
alloy sheet by surface polishing, "Magnesium Technology 2010" TMS, Seattle (2010) 181-186.

J. Kim, K.C. Wong, P.C. Wong, S.A. Kulinich, J.B. Metson, K.A.R. Mitchell, Characterization of AZ91 magnesium alloy and organosilane adsorption on its surface, Appl. Surf. Sci. 253 (2007) 4197-4207. investigation of naturally formed oxide films on pure magnesium, Corros. Sci. 39 (1997) 1397-1414.

[37] S.J. Splinter, N.S. McIntyre, The initial interaction of water-vapor with Mg-Al alloy surfaces at room temperature, Surf. Sci., 314 (1994) 157-171.

R. Lindström, J.E. Svensson, L.G. Johansson, The influence of carbon dioxide on the atmospheric corrosion of some magnesium alloys in the presence of $\mathrm{NaCl}$, ,J. Electrochem. Soc. 149 (2002) B103-B107. R. Lindström, L-G. Johansson, G.E. Thompson, P. Skeldon, J-E. Svensson, Corrosion of magnesium in humid air, Corros. Sci.,46 (2004) $1141-1158$.

[40] M. Jönsson, D. Persson, R. Gubner, The initial steps of atmospheric corrosion on magnesium alloy AZ91D, J. Electrochem. Soc. 154 (2007) C684-C691. 
M. Jönsson, D. Persson, D. Thierry, Corrosion product formation during $\mathrm{NaCl}$ induced atmospheric corrosion of magnesium alloy AZ91D, Corros. Sci. 49 (2007) 1540-1558.

J.H. Nordlien, S. Ono, N. Masuko, K. Nisancioglu, Morphology and structure of oxide-films formed on magnesium by exposure to air and water, J. Electrochem. Soc. 142 (1995) 3320-3322.

[43] G. Baril, N. Pebere, The corrosion of pure magnesium in aerated and deaerated sodium sulphate solutions, Corros. Sci. 43 (2001) 471484.

[44] G. Song, A. Atrens, D. Stjohn, J. Naim, Y. Li, The electrochemical corrosion of pure magnesium in $1 \mathrm{~N} \mathrm{NaCl}$, Corros. Sci. 39 (1997) 855875.

[45] R. Lindström, L.G. Johansson, J-E. Svensson, The influence of $\mathrm{NaCl}$ and $\mathrm{CO} 2$ on the atmospheric corrosion of magnesium alloy AZ91, Mat. and Corros. 54 (2003) 587-594.

[46] S. Mathieu, C. Rapin, J. Steinmetz, P. Steinmetz, A corrosion study of the main constituent phases of AZ91 magnesium alloys, Corros. Sci. 45 (2003) 2741-2755.

[47] G. Song, A. Atrens, Recent insights into the mechanism of magnesium corrosion and research suggestions, Adv. Eng. Mat. 9 (2007) 177-183.

[48] G. L. Makar, J. Kruger, Corrosion studies of rapidly solified magnesium alloys, J. Electrochem. Soc. 137 (1990) 414-421. 
M. Anik, G. Celikten, Analysis of the electrochemical reaction behavior of alloy AZ91 by EIS technique in $\mathrm{H}_{3} \mathrm{PO}_{4} / \mathrm{KOH}$ buffered $\mathrm{K}_{2} \mathrm{SO}_{4}$ solutions, ,Corros. Sci. 49 (2007) 1878-1894.

[50] analysis of multi-element oxide thin films by angle-resolved XPS: Application to ultra-thin oxide films on MgAl substrates, Appl. Surf. Sci. 253 (2006) 627-638.

[51] C.L. Liu, Y.C. Xin, X.B. Tian, P.K. Chu, Corrosion behavior of AZ91 magnesium alloy treated by plasma immersion ion implantation and deposition in artificial physiological fluids, Thin Solid Films 516 (2007) 422-427.

[52] H. M. Wang, Y. Li, F. H. Wang, Influence of cerium on passivity behavior of wrought AZ91 alloy, Electrochim. Acta 54 (2008) 706-713. analysis and oxidation behavior of $\mathrm{Y}$-ion implanted $\mathrm{AZ31}$ magnesium alloys, Appl. Surf. Sci. 253 (2007) 3574-3580. tantalum ion implantation on the corrosion behavior of AZ31 magnesium alloys, J. Alloy. Comp. 437 (2007) 87-92. cerium implantation on the oxidation behavior of AZ31 magnesium alloys, J. Alloy.Comp. 456 (2008) 384-389. implantation, Nucl. Instr. Meth. Phys. Res. B 263 (2007) 401-406. 
[57] L. Wang, T. Shinohara, B.P. Zhang, H, Iwai, Characterization of surface products on AZ31 magnesium alloy in dilute $\mathrm{NaCl}$ solution, $\mathrm{J}$. Alloy. Comp. 485 (2009) 747-752.

R. Souda, Y. Hwang, T. Aizawa, W. Hayami, K Oyoshi., S. Hishita, Ca segregation at the $\mathrm{MgO}(001)$ surface studied by ion scattering spectroscopy, Surf. Sci. 387 (1997) 136-141. surface pre-treatment on the growth kinetics and chemical constitution of ultra-thin oxide films on Al-Mg alloy substrates, Surf. Sci. 604 (2010) 587594.

[60] T.S. Shih, J.B. Liu, P.S. Wei, Oxide films on magnesium and magnesium alloys, Mater. Chem. Phys. 104 (2007) 497-504.

[61] T. Nakano, S. Sato, S. Baba, Structural analysis of Cu-In alloy films with XPS depth profiling by ion etching, Vacuum 74 (2004) 591-594.

[62] B.R. Strohmeier, An ESCA method for determining the oxide thickness on Aluminium-alloys, Surf. Interface Anal. 15 (1990) 51-56.

[63] S. Tanuma, C.J. Powell, D.R. Penn, Calculations of electron inelastic mean free paths. 2. Data for 27 elements over the $50-2000 \mathrm{eV}$ range, Surf. Interface Anal. 17 (1991) 911-926.

A. Akkerman, T. Boutboul, A. Breskin, R. Chechik, A. Gibrekhterman, Y. Lifshitz, Inelastic electron interactions in the energy range $50 \mathrm{eV}$ to $10 \mathrm{keV}$ in insulators: Alkali halides and metal oxides, Phys. Stat. Sol (b) 198 (1996) 769-784. 
[65] C.J. Powell, A. Jablonski, NIST Electron Inelastic-Mean-Free-Path Database, SRD 71, US Department of Commerce, National Institute of Standards and Technology, Gaithersburg, MD (2000)

[66] E. McCafferty, J.P. Wightman, An X-ray photoelectron spectroscopy sputter profile study of the native air-formed oxide film on titanium, J. Appl. Surf. 143 (1999) 92-100.

[67] S. Feliu Jr, M.J. Bartolomé, Influence of alloying elements and etching treatment on the passivating films formed on aluminium alloys Surf. Interface Anal. 39 (2007) 304-316.

[68] T. Nenadovic, B. Perraillon, Z. Bogdanov, Z. Djordjevic, M. Milic, Sputtering and surface-topography of oxides, Nucl. Instr. Meth. Phys. Res. B 48 (1990) 538-543.

\section{Figure captions.}

Figure 1. SEM micrographs: (a) AZ31 alloy, (b) AZ61 alloy.

Figure 2. XPS Mg 2p spectra of the AZ31 and AZ61 alloy in polished and asreceived condition.

Figure 3. Element percentages obtained by XPS on the outer surfaces of the AZ31 and AZ61 alloy in polished and as-received condition and after sputtering. Figure 4. XPS Al 2s spectra of the AZ31 and AZ61 alloy in polished and asreceived condition.

Figure 5. XPS C1s spectra of the AZ31 and AZ61 alloy in polished condition.

Figure 6. SEM micrographs: (a) AZ61 alloy in polished condition, (b) AZ61 alloy in as-received condition. 
Figure 7. Oxide thickness obtained by XPS on AZ31 and AZ61 alloy in polished and as-received condition after sputtering.

Figure 8. Low angle XRD pattern for the AZ3 and AZ61 alloys in "as-received condition".

Figure 9. Nyquist plots for the AZ31 and AZ61 alloy in polished and as-received condition.

Table 1. Chemical composition of Mg-Al alloys (wt\%)

\begin{tabular}{|l|l|l|l|l|l|l|l|l|l|l|}
\hline Material & Al & Zn & $\mathrm{Mn}$ & $\mathrm{Si}$ & $\mathrm{Cu}$ & $\mathrm{Fe}$ & $\mathrm{Ni}$ & $\mathrm{Ca}$ & $\mathrm{Zr}$ & Others \\
\hline AZ31 & 3.1 & 0.73 & 0.25 & 0.02 & $<0.001$ & 0.005 & $<0.001$ & 0.0014 & $<0.001$ & $<0.30$ \\
\hline AZ61 & 6.2 & 0.74 & 0.23 & 0.04 & $<0.001$ & 0.004 & $<0.001$ & 0.0013 & $<0.001$ & $<0.30$ \\
\hline
\end{tabular}


Table 2. Areas of $\mathrm{CO}_{3}{ }^{2-}$ from fitting of $\mathrm{C} 1 \mathrm{~s}$ peak (in $\mathrm{CPS}$ eV)

\begin{tabular}{|l|l|l|}
\hline & \multicolumn{2}{|l|}{ Polished condition } \\
\hline $\begin{array}{l}\text { Sputtering time } \\
\text { (minutes) }\end{array}$ & AZ31 alloy & AZ61 alloy \\
\hline 0 & 173 & 177 \\
\hline 0.5 & 179 & 204 \\
\hline 1.25 & 116 & 164 \\
\hline 2 & 63 & 91 \\
\hline
\end{tabular}


Table 3. Atomic percentage observed by XPS on outer surface of alloys AZ31 and AZ61 in polished and as-received condition, and variation with sputtering time

\begin{tabular}{|c|c|c|c|c|c|c|c|c|}
\hline & $\begin{array}{l}\text { Sputtering } \\
\text { time (min) }\end{array}$ & $\% \mathrm{C}$ & $\% \mathrm{O}$ & $\% M g$ & $\% \mathrm{Al}$ & $\% \mathrm{Ca}$ & $\mathrm{O} /(\mathrm{Mg}+\mathrm{Al})$ & $\begin{array}{l}\mathrm{Al} /(\mathrm{Mg}+\mathrm{Al}) \\
\times 100\end{array}$ \\
\hline \multicolumn{9}{|c|}{ Polished condition } \\
\hline \multirow[t]{3}{*}{ AZ31 } & 0 & 51 & 35 & 12 & 2 & 0 & 2.5 & 14 \\
\hline & 5 & 0 & 41 & 54 & 5 & 0 & 0.7 & 8 \\
\hline & 10 & 0 & 19 & 77 & 4 & 0 & 0.2 & 4 \\
\hline \multirow[t]{3}{*}{ AZ61 } & 0 & 37 & 47 & 13 & 3 & 0 & 2.9 & 19 \\
\hline & 5 & 0 & 46 & 46 & 8 & 0 & 0.9 & 15 \\
\hline & 10 & 0 & 23 & 70 & 7 & 0 & 0,3 & 9 \\
\hline \multicolumn{9}{|c|}{ As-received condition } \\
\hline \multirow[t]{7}{*}{ AZ31 } & 0 & 51 & 30 & 16 & 2 & 1 & 1.7 & 11 \\
\hline & 5 & 0 & 55 & 40 & 5 & 0 & 1.2 & 11 \\
\hline & 10 & 0 & 54 & 40 & 6 & 0 & 1.2 & 13 \\
\hline & 15 & 0 & 54 & 40 & 6 & 0 & 1.2 & 13 \\
\hline & 20 & 0 & 51 & 43 & 6 & 0 & 1.0 & 12 \\
\hline & 30 & 0 & 46 & 48 & 6 & 0 & 0.9 & 11 \\
\hline & 40 & 0 & 40 & 53 & 7 & 0 & 0.7 & 12 \\
\hline \multirow[t]{7}{*}{$\overline{A Z 61}$} & 0 & 65 & 23 & 9 & 2 & 1 & 2.0 & 18 \\
\hline & 5 & 0 & 60 & 28 & 12 & 0 & 1.5 & 30 \\
\hline & 10 & 0 & 59 & 29 & 12 & 0 & 1.4 & 29 \\
\hline & 15 & 0 & 57 & 32 & 11 & 0 & 1.3 & 25 \\
\hline & 20 & 0 & 52 & 38 & 10 & 0 & 1.0 & 21 \\
\hline & 30 & 0 & 44 & 49 & 7 & 0 & 0.8 & 12 \\
\hline & 40 & 0 & 27 & 68 & 5 & 0 & 0.4 & 7 \\
\hline
\end{tabular}


Table 4. EDX analyses of polished and "as received" surfaces of AZ61 alloys

\begin{tabular}{|l|l|l|l|l|}
\hline Sample & Spectrum & $\% \mathrm{Mg}$ & $\% \mathrm{Al}$ & $\% \mathrm{Zn}$ \\
\hline \multirow{3}{*}{$\begin{array}{l}\text { AZ61 in } \\
\text { Polished }\end{array}$} & 1 & & & \\
\cline { 2 - 5 } & 2 & 93.51 & 5.61 & 0.88 \\
\cline { 2 - 5 } & 3 & 93.29 & 5.81 & 0.90 \\
\cline { 2 - 5 } & 4 & 93.29 & 5.64 & 1.06 \\
\hline \multirow{2}{*}{$\begin{array}{l}\text { AZ610 in “as } \\
\text { received } \\
\text { condition" }\end{array}$} & 1 & 93.74 & 5.52 & 0.75 \\
\cline { 2 - 5 } & 2 & 91.75 & 7.50 & 0.75 \\
\cline { 2 - 5 } & 3 & 93.30 & 5.79 & 0.91 \\
\cline { 2 - 5 } & 4 & 93.36 & 5.76 & 0.88 \\
\hline
\end{tabular}


Table 5. Comparison of $R_{H F}$ values with XPS features

\begin{tabular}{|l|l|l|}
\hline Specimens & EIS measurements & Special features $\left({ }^{*}\right)$ \\
\cline { 2 - 3 } & RHF $(\Omega . c m 2)$ & (Inferred from XPS results) \\
\hline As-received AZ31 & 300 & B \\
\hline Freshly polished AZ31 & 1000 & A \\
\hline As-received AZ61 & 1200 & B, D \\
\hline Freshly polished AZ61 & 4000 & A, B, C \\
\hline
\end{tabular}

$\left.{ }^{*}\right) A=$ uniformity of oxide film

$B=$ presence of spinel islands

$\mathrm{C}=$ greater thickness

$D=$ higher percentage of surface covered by spinel 

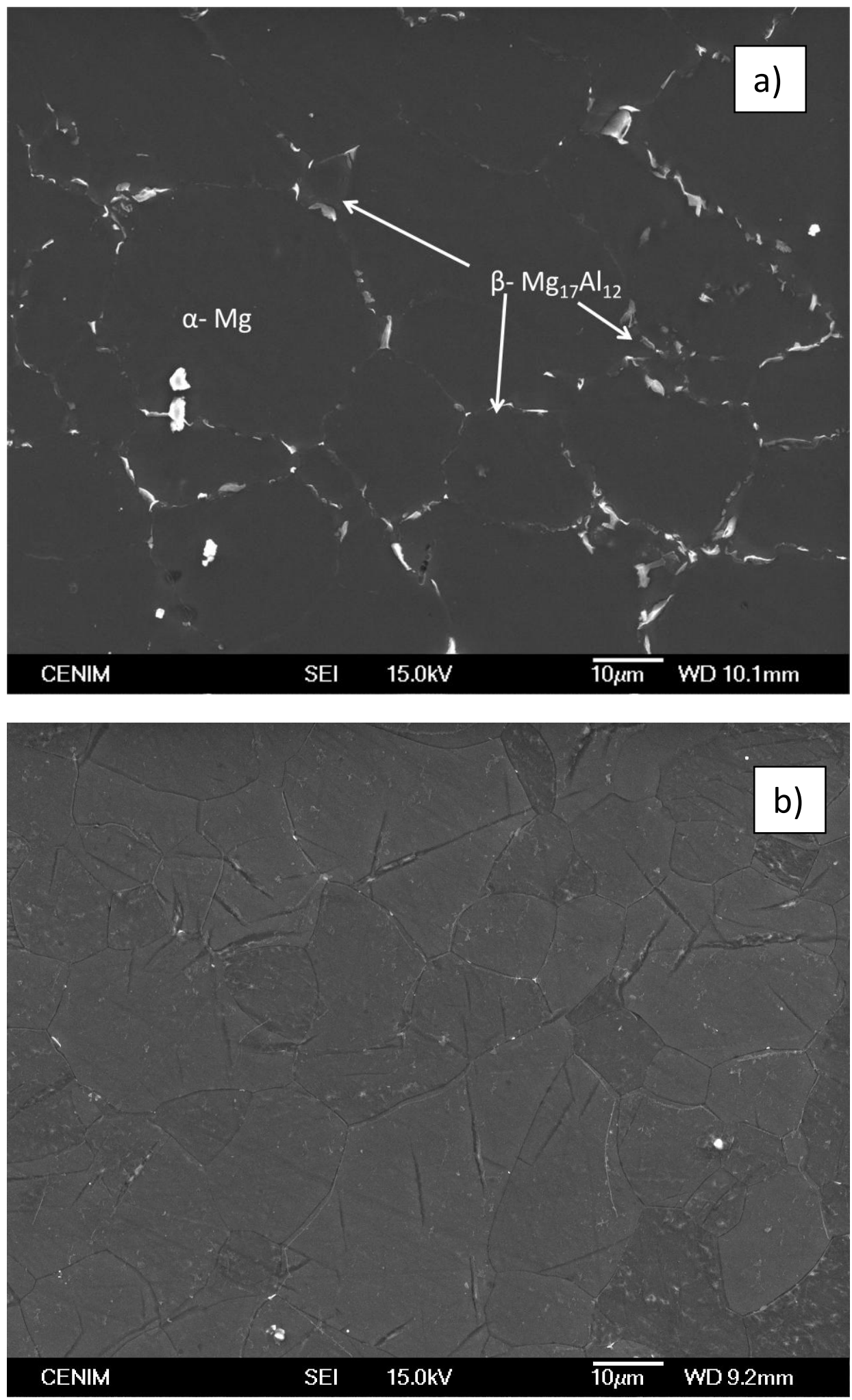

Figure 1. 


$\begin{array}{lllll} & \text { AZ31 in } & \text { AZ61 in } & \text { AZ31 in } & \text { AZ61 in } \\ \text { polished } & \text { polished } & \text { "as-received" } & \text { "as-received" } \\ \text { condition } & \text { condition } & \text { condition } & \text { condition }\end{array}$

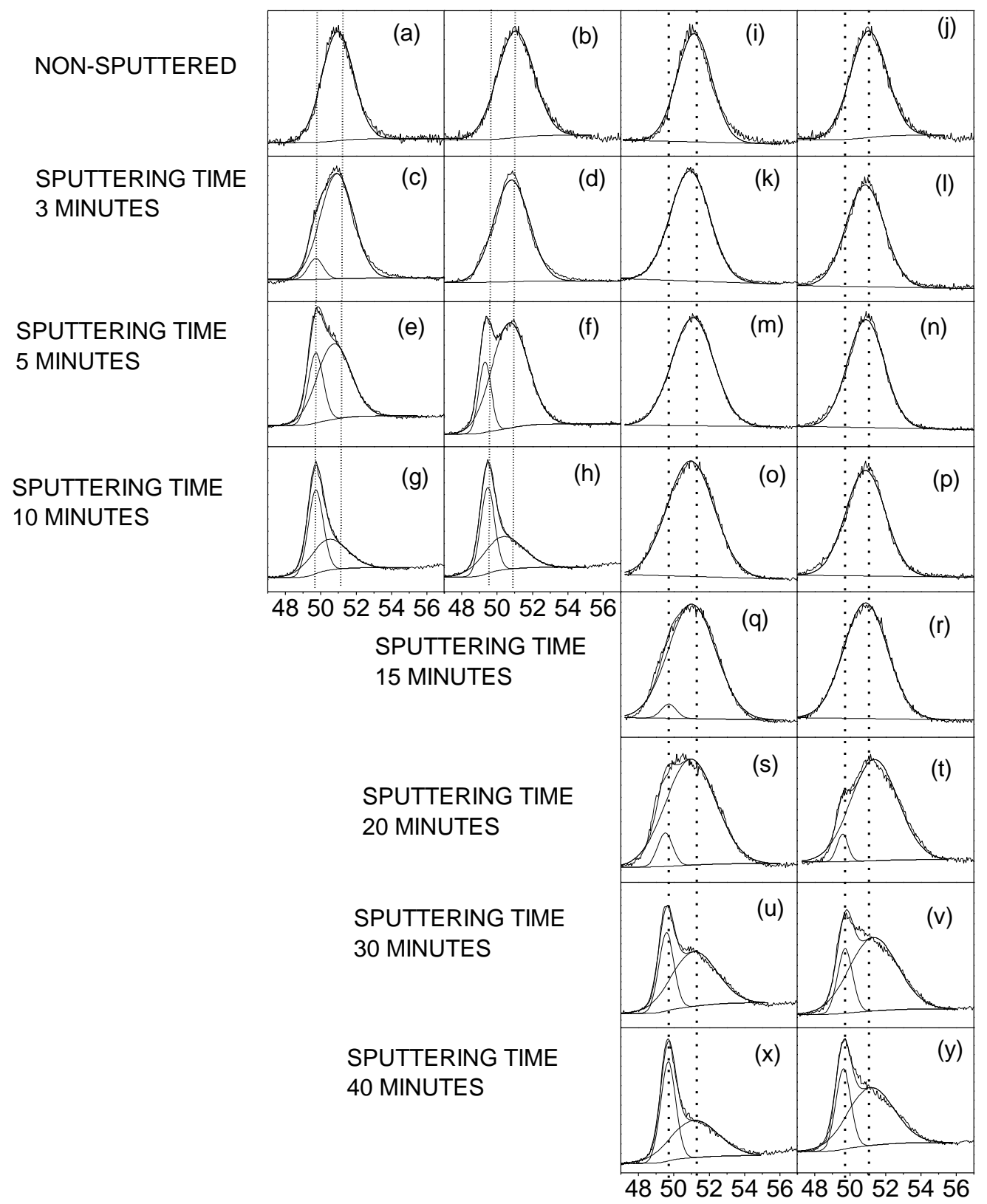

Binding energy (eV)

Figure 2 


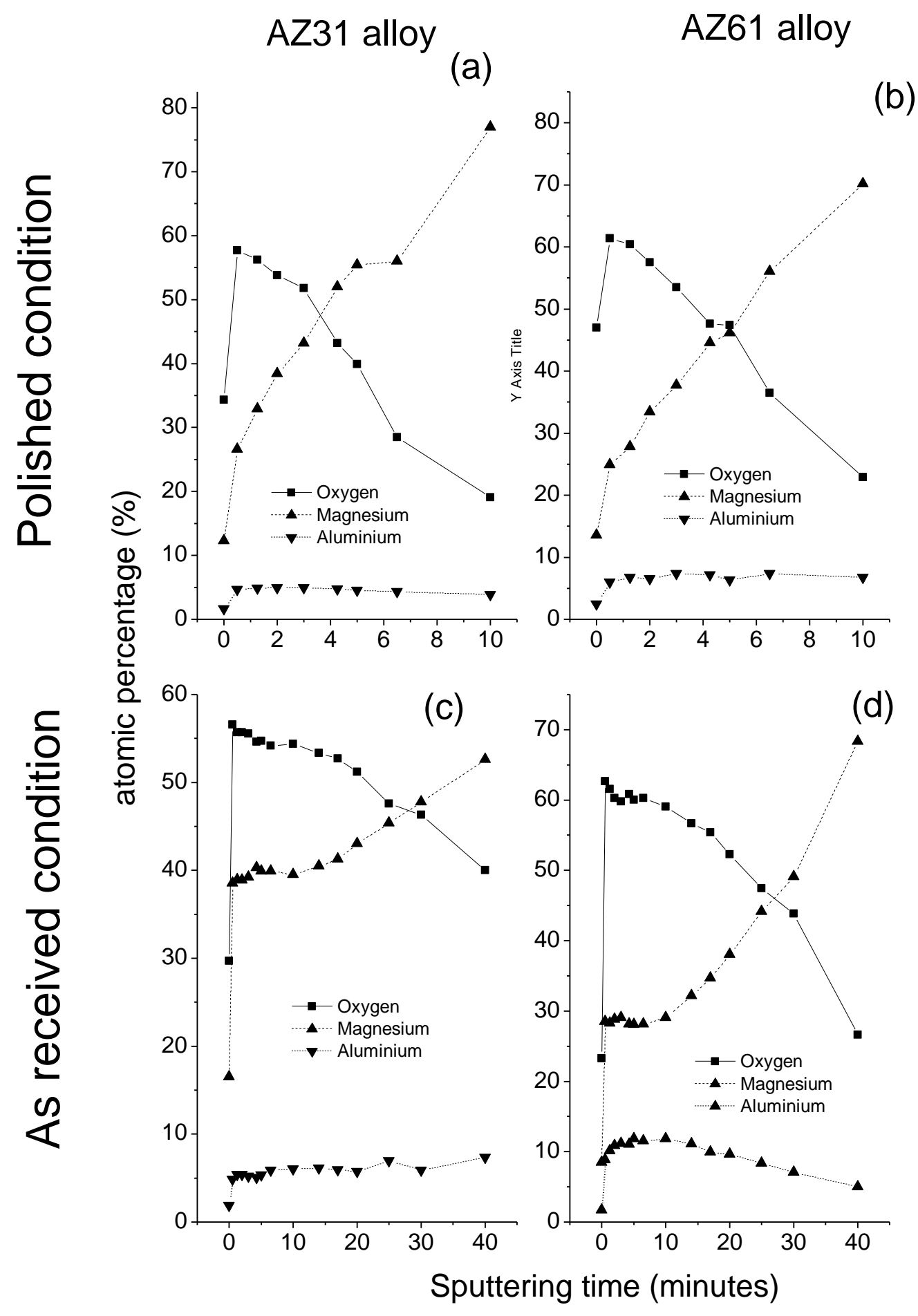

Figure 3 


$\begin{array}{llll}\text { AZ31 in } & \text { AZ61 in } & \text { AZ31 in } & \text { AZ61 in } \\ \text { polished } & \text { polished } & \text { "as-received" } & \text { "as-received" } \\ \text { condition } & \text { condition } & \text { condition } & \text { condition }\end{array}$

\section{Al 2s PEAK}

NON-SPUTTERED

SPUTTERING TIME 3 MINUTES

SPUTTERING TIME 5 MINUTES

SPUTTERING TIME 10 MINUTES

SPUTTERING TIME 15 MINUTES

SPUTTERING TIME 20 MINUTES

SPUTTERING TIME 30 MINUTES

SPUTTERING TIME 40 MINUTES

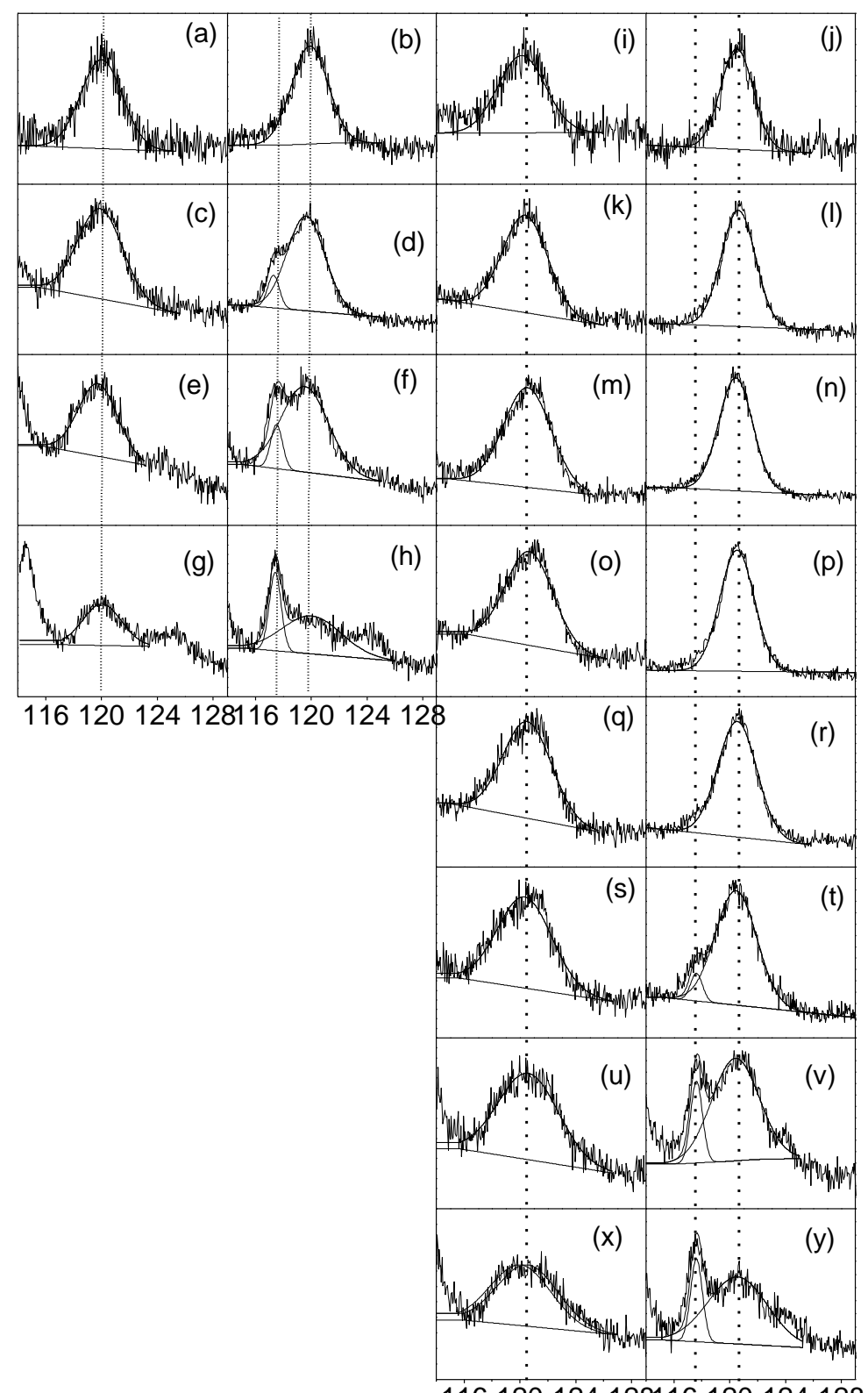

116120124128116120124128

Binding energy $(\mathrm{eV})$

Figure 4 


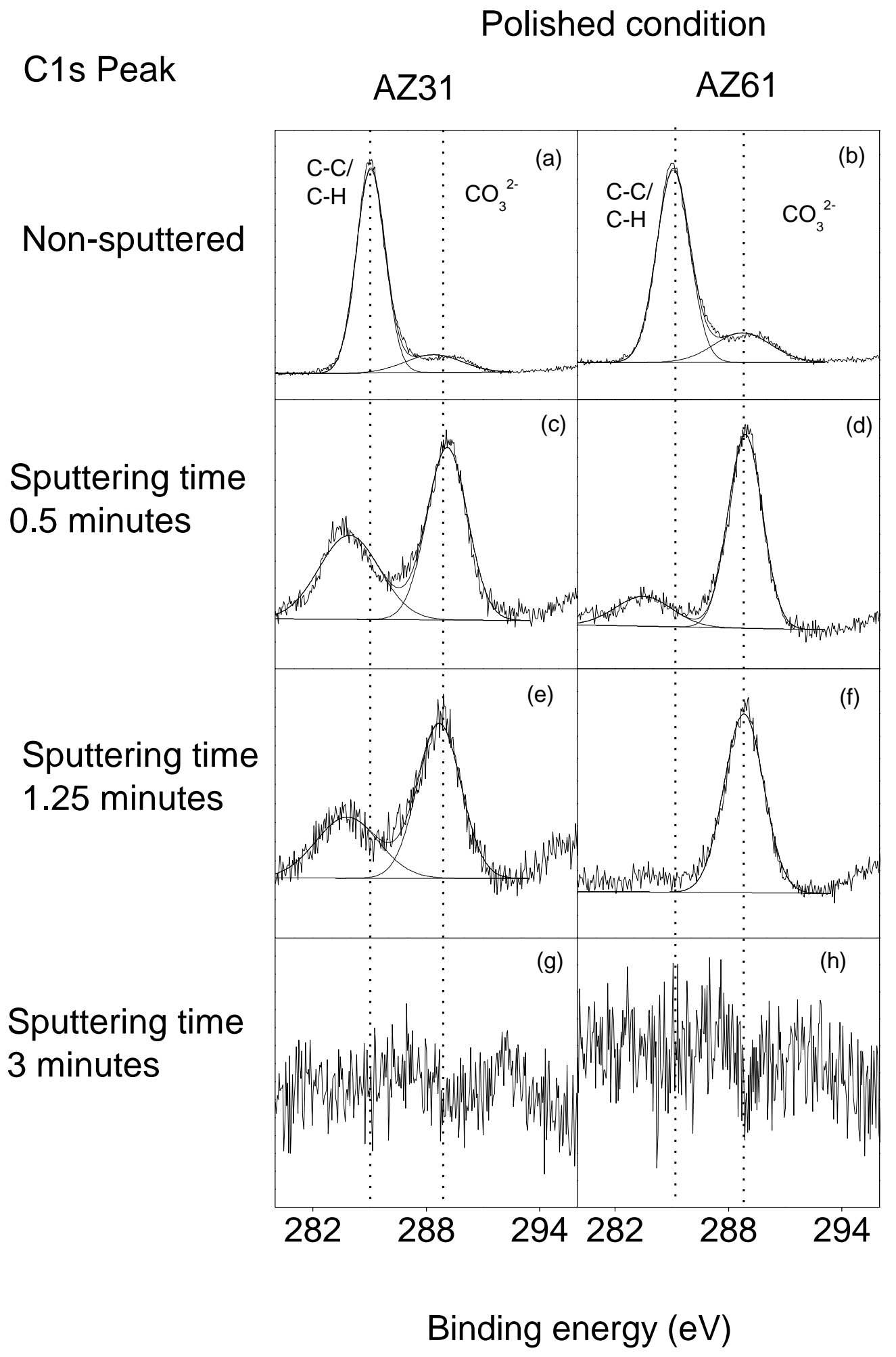

Figure 5. 


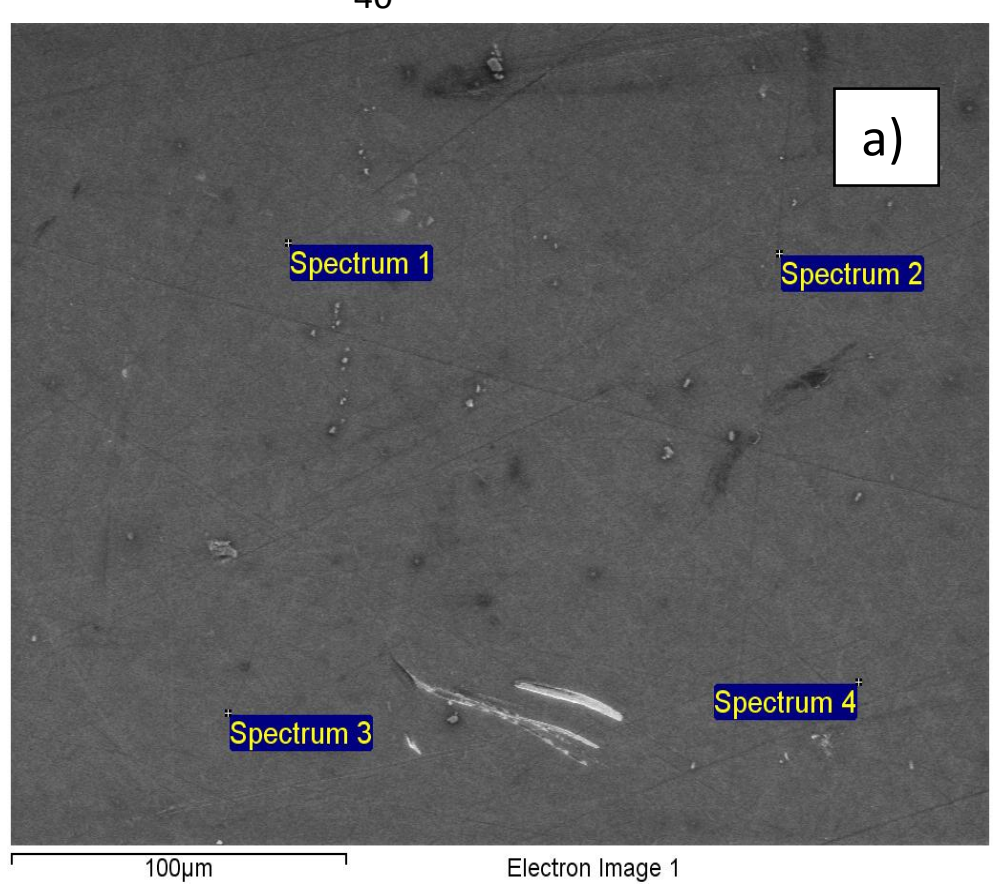

AZ61

in

Polished

Condition

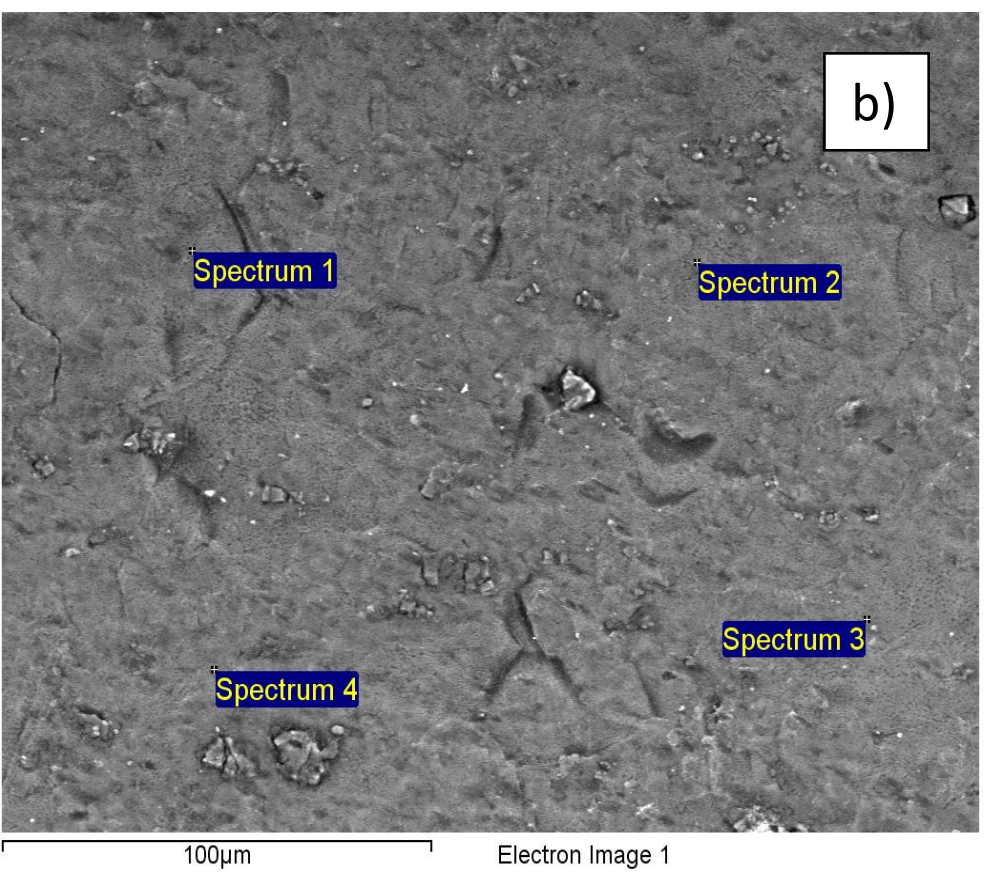

Condition

Figure 6 
Polished Condition "As-received" Condition

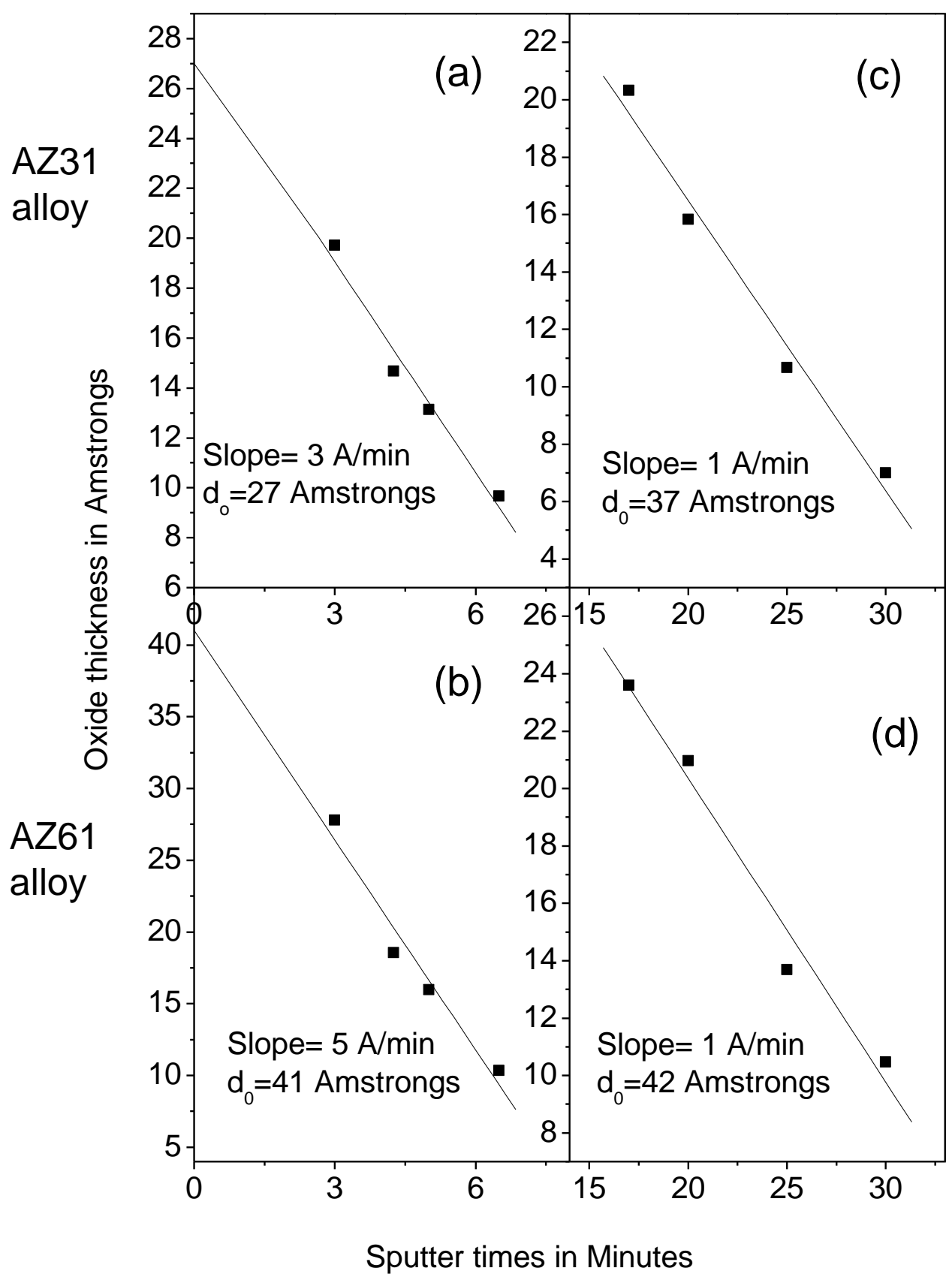

Figure 7. 
"As-received" condition

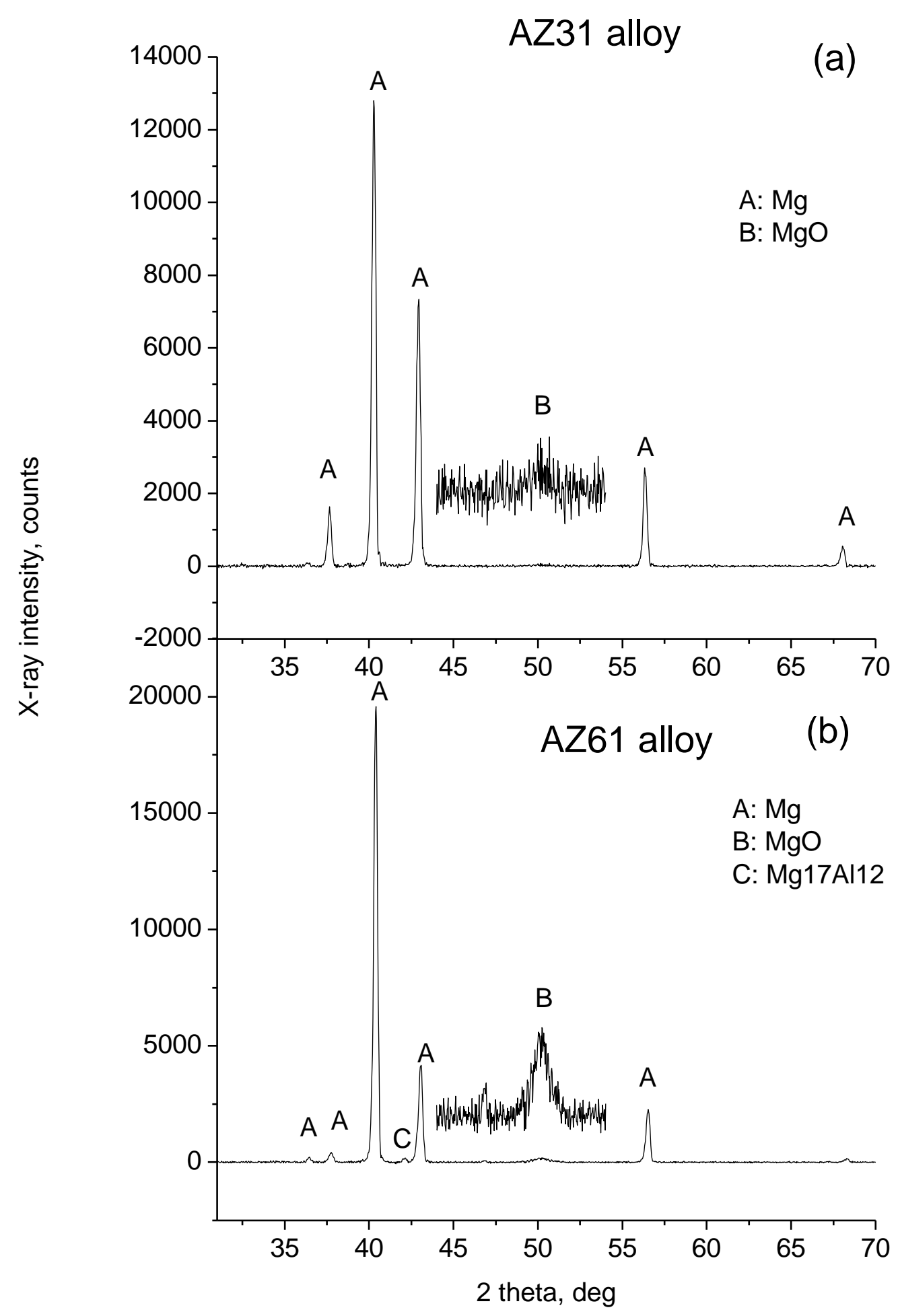

Figure 8 


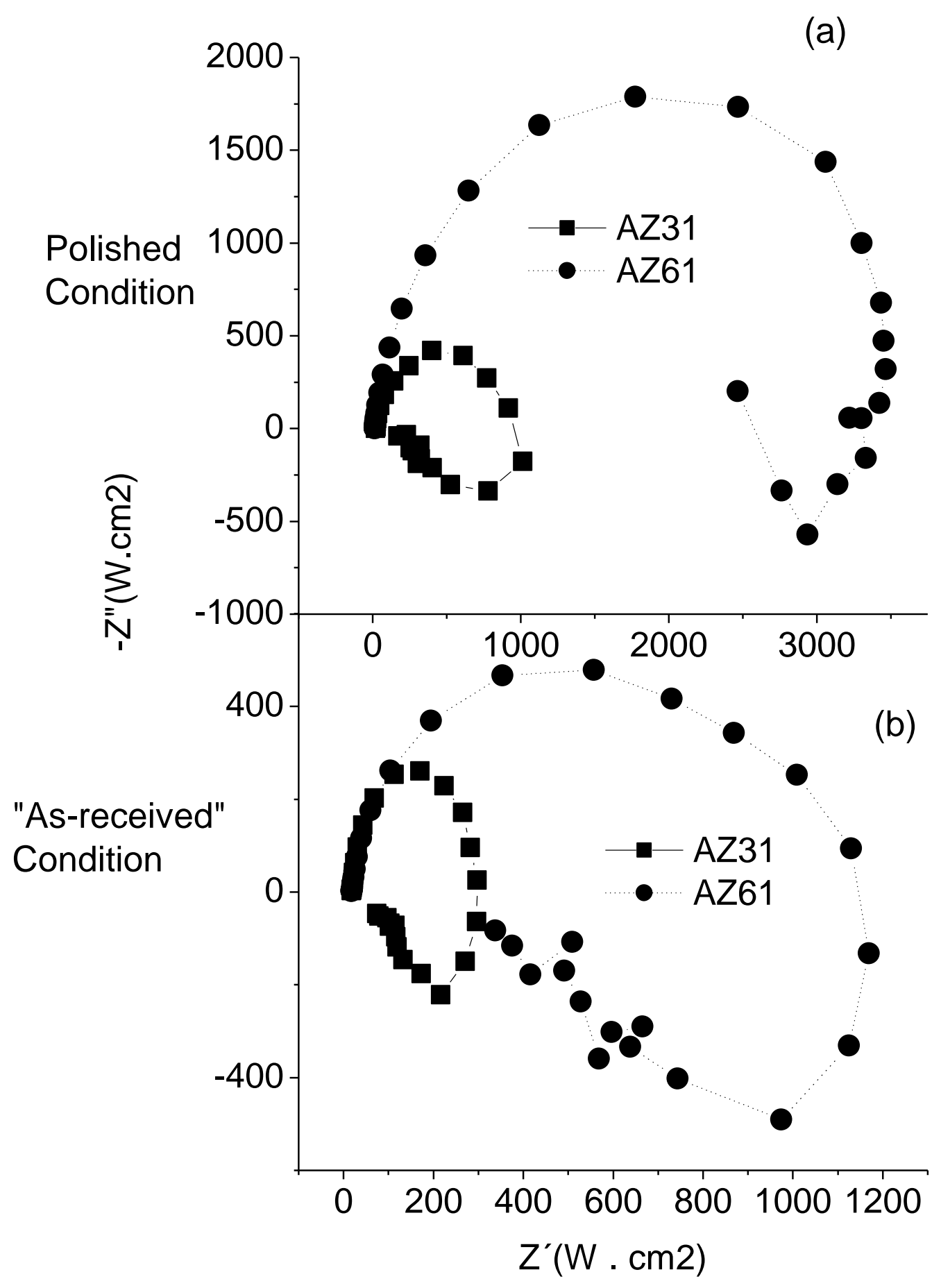

Figure 9. 